\title{
DAS FAMILIAS TRADICIONAIS ÁS FAMÍLIAS CONTEMPORÂNEAS: DESAFIOS E PERSPECTIVAS DAS POLÍTICAS PÚBLICAS
}

\section{FAMILIES OF TRADITIONAL FAMILIES CONTEMPORARY: CHALLENGES AND PROSPECTS OF PUBLIC POLICY}

\author{
${ }^{1}$ Rita de Cassia Barros de Menezes \\ ${ }^{2}$ Diogo De Calasans Melo Andrade
}

\section{RESUMO}

Sendo a família uma das mais importantes e valorizadas Instituições Sociais, o tema das políticas públicas destinadas a elas carece de discussão, atraindoas atenções para os atuais modelos que vêm sofrendo evolução, não podendo o Direito e o Estado fecharem os olhos para essa nova realidade. Diante desta situação, o presente artigo analisa as fontes do Direito, como formas extensivas de interpretação no sistema jurídico, afim de, justificar o reconhecimento de novos modelos de família que vêm surgindo na contemporaneidade, bem como a utilização das referidas fontes como possibilidade de concessão de políticas públicas jáimplementadaspara famílias tradicionais.

Palavras-chave: Famílias tradicionais, Contemporâneas, Políticas públicas

\begin{abstract}
Beingthefamilyoneofthemostimportantandvalued social institutions, theissueofpublic policies aimedatthemlacksdiscussion, drawingattentiontothecurrentmodelsthathavebeenevolution, cannotthelawandthestateturning a blindeyetothis new reality. Facedwiththissituation, thisarticleanalyzesthesourcesoflaw, as extensiveformsofinterpretation in the legal system in ordertojustifytherecognitionof new familymodelsthathaveemerged in contemporary times, andthe use ofsuchsources as thepossibilityofgrantingpublic policies implementedtotraditionalfamilies.
\end{abstract}

Keywords: Traditionalfamilies, Contemporary, Publicpolicy

\footnotetext{
${ }^{1}$ Doutoranda em Direito Político e Econômico pela Universidade Presbiteriana Mackenzie - MACKENZIE, São Paulo, SP, (Brasil). Professora da Universidade Tiradentes, Universidade Tiradentes - Campus II, Aracaju, SE. Email: ritacassiamenezes@uol.com.br.

${ }^{2}$ Doutorando em Direito Político e Econômico pela Universidade Presbiteriana Mackenzie, MACKENZIE, São Paulo, SP, (Brasil.) Professor na Universidade Tiradentes - UNIT, Aracaju, SE.E-mail: contato@diogocalasans.com.
} 


\section{INTRODUÇÃO}

Através da nova forma de interpretação da Constituição Federal, pautada na valorização dos Princípios Constitucionais, trazida pelo neoconstitucionalismo, novos arranjos familiares passaram a ser reconhecidos, e o direito de família deixou de pertencer exclusivamente ao direito privado e passou a ser estudado também pelo direito público, tendo em vista o interesse do Estado na Instituição Familiar.

Desta forma, com a constitucionalização do direito civil, a família que até então era normatizada pelo direito privado, passou a sofrer a interferência do Estado, com direitos reconhecidos e interpretados à luz da Constituição, restaurando a unidade daquilo que chamamos de sistema jurídico.

A Constituição Federal de 1988, tida como a mais democrática e cidadã frente às anteriores, permitiu alterações nas relações entre o Estado e sociedade dando preponderância aos Princípios Constitucionais, a exemplo da Igualdade e Liberdade, refletindo assim, diretamente nas ações individuais dos cidadãos e nas relações familiares estabelecidas entre

eles.

Nesse contexto, diante de tantas modificações ocorridas na Família, para se discutir o tema sobre as políticas públicas do Estado voltados aos seus atuais arranjos, faz-se necessário enfrentar imperativamente o problema da efetividade dessas políticas no ambiente jurídico da sociedade brasileira, em defesa dos Princípios da Igualdade e da Liberdade, como imperativos categóricos.

Sendo assim, o presente trabalho procura demonstrar que para a efetividade da cidadania, o direito brasileiro não pode ignorar os atuais arranjos familiares, discutindo-se a criação de novas políticas públicas voltadas a eles, bem como a interpretação através das fontes do direito, estendo as políticas públicas já existentes para as famílias tradicionais aos novos arranjos familiares, tendo em vista que, ao que parece, os programas de políticas públicas propostos, em geral, destinam-se aos modelos tradicionais de estrutura familiar

\section{A UTILIZAÇÃO DAS FONTES E DOS PRINCÍPIOS DO DIREITO NOS CASOS OMISSOS EM LEI}


Durante longo período, o Direito foi marcado pela teoria positivista, ou seja, tinha a lei como fonte de validação dos atos na sociedade e aquilo que não fosse previsto em lei, não tinha validade jurídica.

Assim, o direito foi marcado pelo isolamento da política e da moral, que no entendimento de Mascaro, na obra Crítica da Legalidade e do Direito Brasileiro, a partir do século XIX, fez confundir direito com normas positivadas pelo Estado. Após este período, onde o direito só era compreendido a partir da norma jurídica, (MASCARO, 2008) observouse que as leis não mais correspondiam aos anseios sociais e não resolviam os conflitos surgidos na sociedade, que dada às suas mudanças, passou a exigir uma postura menos autoritária do que as impostas pelo positivismo na solução dos conflitos.

A ideia de impor um isolamento entre a criação e a aplicação da lei prescreve aos aplicadores do direito uma limitação, separando os fatos das normas, não podendo estes, decidirem, conforme suas próprias considerações morais.

Segundo Rafael Lazzarotto Simioni (2015, p. 142):

O positivismo de Hans Kelsen joga um balde de água gelada sobre a pretensão dos juristas de conquistar, via metodologia, a tão sonhada segurança do direito. Ele desmonta a esperança de se garantir a certeza e a previsibilidade da interpretação jurídica. Tão mal compreendido quanto pouco estudado, os déficits na interpretação do pensamento de Hans Kelsen ilustram bem o quanto é possível se enganar na interpretação baseada em textos.

Assim definitivamente, o positivismo jurídico defendido por Kelsen não mais atendia às perspectivas da sociedade.

Frente a esta nova postura social faz-se necessário considerar o que diz Sampaio Ferraz em seu livro Introdução ao Estudo do Direito, quando aponta que o sistema jurídico tem caráter dinâmico, em um processo de contínua transformação, onde as normas devem ser substituídas ou perdem sua atualidade em decorrência de alterações nas situações normatizadas. (FERRAZ,

2015).

$\mathrm{O}$ direito e sociedade se complementam e se fundem, tendo em vista que com a evolução da sociedade, surge a necessidade de criação de novos paradigmas jurídicos, através de novas leis com a finalidade de regular os principais acontecimentos do ser humano em relação à vida

social. 
Ferrajoli supõe mudanças fundamentais em relação à maneira de entender a estrutura do direito e da jurisdição, (FERRAJOLI, 2009), no seu entendimento, a função essencial da ciência

jurídica é a de mostrar, tratar de corrigir as lacunas e contradições geradas pela violação dos direitos, e a jurisdição na medida em que tem de ver-se como aplicação e interpretação das leis em conformidade com a Constituição, incorporando um papel dogmático e de responsabilidade cívica.

Uma vez que a sociedade avança a passos largos, surgem situações que não são previstas juridicamente, a exemplo das famílias que vêm se remodelando, formando novos arranjos familiares e necessitam de um posicionamento do Estado em relação a estas novas configurações reconhecidas pelo Judiciário.

Nesta situação, assim como em outras lacunas da lei, as fontes do direito devem ser buscadas, entre elas, analogia, costumes, doutrina, jurisprudência, Princípios Gerais do Direito de modo a resolver o caso concreto.

No entendimento de Maria Clara Falavigna (2007, p. 108) os princípios gerais estão inseridos no sistema jurídico e são utilizados como um subsídio no modo interpretativo na elaboração de uma decisão, assim como preconiza o art. $4^{\circ}$ da Lei de Introdução do Código Civil, que aduz que os princípios gerais serão aplicados quando houver omissão da lei para um determinado caso concreto, devendo-se antes utilizar a analogia e os costumes.

Diante da evolução social e da necessidade de interpretação das leis de modo a solucionar os casos concretos, em 1988 surge no Brasil, uma nova perspectiva do Direito e do Estado, denominada neoconstitucionalismo, ou seja, um novo modelo de organização política, atendendo as aspirações da sociedade, presente na Constituição Federal, trazendo uma nova forma de interpretação constitucional e uma nova concepção de direitos fundamentais edificados sobre o fundamento dos princípios previstos constitucionalmente.

Nas palavras de Galvão: "O neoconstitucionalismo tem como ferramentas interpretativas a aplicação direta da efetividade de princípios constitucionais e a prática da ponderação de valores" (GALVÃO, 2012, p. 129).

Para Samir José Caetano Martins (2007):

No Brasil, coube à vigente Constituição Federal o papel de referência legislativa desta corrente de pensamento, que tem como um de seus principais vetores a constitucionalização dos diversos setores do ordenamento jurídico, impregnando todas as normas infraconstitucionais com o teor da outrora vagamente definida como "Carta Política", fenômeno que revolucionou o modo de interpretação e aplicação de todas as normas jurídicas, trazendo a reboque especulações que tornaram mais 
complexo o raciocínio jurídico e menos evidente a racionalidade das decisões judiciais.

Nesse contexto, a partir da Constituição Federal de 1988, os Princípios, que até então eram utilizados como uma das fontes do Direito, passaram a ser utilizados como normas inclusive sendo aplicados aos casos não previstos juridicamente.

Para Duarte, os Princípios são normas com um grau de generalidade relativamente alto, enquanto que as regras são normas com um grau de generalidade relativamente baixo, assim

segundo a teoria anti-positivista de Dworkin, o sistema jurídico, inclui não somente o direito explícito e as fontes do direito, mas também um conjunto de princípios hierarquicamente ordenados e que estão implícitos ou não pressupostos pelo direito explícito. (DUARTE, 2013,

p. $57)$.

Assim, o neoconstitucionalismo possibilitou a efetivação de cidadania, através de uma nova forma de interpretação das leis, valorizando-se os Princípios Constitucionais, pautados na igualdade e liberdade do cidadão, conformes os preceitos de um Estado Democrático de Direito.

Na visão de Luís Prieto Sanchís (2003, p. 11):

Más principios que reglas; más ponderación que subsunción; omnipresencia de la Constitución en todas las áreas jurídicas y en todos los conflictos minimamente relevantes, en lugar de espacios exentos en favor de la opción legislativa o reglamentaria; omnipotencia judicial en lugar de autonomía del legislador ordinario; y, por último, coexistencia de una constelación plural de valores, a veces tendencialmente contradictorios, en lugar de homogeneidad ideológica.

Nesse contexto, o direito brasileiro passou a valorizar a importância dos princípios constitucionais, dos direitos fundamentais e a efetividade de sua aplicação, como forma de preservar os fundamentos da democracia e cidadania definindo novos paradigmas, adotando métodos hermenêuticos marcados pela abertura de argumentação e interpretação jurídica dentro dos preceitos da Constituição Federal.

O artigo de Hélcio Ribeiro Constituição, participação e políticas públicas no Brasil, aponta que a discussão sobre o Neoconstitucionalismo vem alterando o cenário jurídico do País ao contribuir para a reformulação da relação entre Constituição e Códigos. Sendo assim, as noções de constitucionalismo social, controle de constitucionalidade, vem se fortalecendo e recebendo ampla importância por parte do Poder Judiciário. (RIBEIRO, 2013, p. 48) 
O Neoconstitucionalismo marcou a passagem de um Estado de Direito para um Estado Democrático de Direito, possibilitando a aplicação dos Princípios Constitucionais nos casos omissos em lei, tornando efetivos os preceitos de cidadania trazidos na Constituição Federal.

\section{O PLURALISMO JURÍDICO COMO EFETIVAÇÃO DA CIDADANIA}

Nesse mesmo sentido, o pluralismo jurídico emerge como vertente teórica que avança nas constatações da teoria jurídica crítica, uma vez que se insere em um quadro que abandona a tradicional dicotomia Estado-sociedade civil e parte para a identificação dos diversos espaços estruturais constitutivos das sociedades capitalistas no sistema mundial contemporâneo, desvelando outras "sociedades civis" com reflexos diretos nas formas de poder, saber e direito. (VENERIO, 2012, p. 73)

Assim como o Neoconstitucionalismo, o pluralismo jurídico observado através de uma teoria crítica reflete a conclusão, de que o modelo positivista presente no Brasil e no Mundo não mais atendem os interesses e anseios sociais, trazendo uma nova forma de interpretação das leis, superando as limitações de interpretação até então existentes, propondo-se a efetivar a cidadania prevista na Carta Magna.

No entendimento de Marcela Gutiérrez (2011):

El multiculturalismo tiene que ver con el proceso de interacción con otros derechos y otros contextos culturales. derechos de reconciliación que buscan -más que determinar prioritariamente lo justo, quien tiene razón o no, mediar entre los adversarios o grupos, para evitar tensiones fuertes en el conjunto de la comunidad.

Sob a perspectiva do pluralismo jurídico, as leis deixaram de ser as únicas fontes do direito, passando-se a valorizar os fenômenos que surgem a partir da complexidade humana e que formam a realidade social, com características próprias, pretendendo-se obter uma maior eficácia jurídica por parte dos aplicadores do direito, como forma de garantir a efetividade da cidadania prevista constitucionalmente em um Estado Democrático de Direito.

De acordo com José Murilo de Carvalho, em seu livro Cidadania no Brasil, o longo caminho, o sentido da cidadania tem a ver com a relação das pessoas com o Estado e com a Nação. Deste modo, aquilo que faz com que as pessoas se tornem cidadãs é a ideia de pertencimento de uma Nação e de um Estado, o que, segundo Carvalho, nem sempre ocorreu 
no Brasil, daí a necessidade de meios eficazes para fazer valer os preceitos constitucionais de cidadania. (CARVALHO, 2010, p. 12).

Assim mais que a previsão constitucional de cidadania, são necessárias também ações afirmativas por parte do Estado, para que a sociedade possa fazer valer este direito e torná-lo efetivo.

Diante da nova concepção de interpretação e aplicação dos direitos fundamentais trazidos pela Constituição Federal, novos paradigmas se impuseram ao ordenamento jurídico brasileiro.

Diante desses novos paradigmas Lênio Streck (2013) em seu livro Hermenêutica Jurídica e (em) crise, aponta que a Constituição precisa corresponder à necessidade de realizar algo contando com a participação da sociedade, assim, os princípios da Igualdade e Liberdade,

além de outros Princípios Constitucionais, tornaram-se elementos referenciais para a interpretação e aplicação das normas jurídicas.

\title{
4. A CONSTITUCIONALIZAÇÃO DO DIRIETO CIVIL E O RECONHECIMENTO DE NOVAS FAMÍLIAS
}

Em relação ao Direito de Família, a Constituição Federal de 1988 representou um momento histórico que respondendo à evolução da sociedade e em consonância com os preceitos do neoconstitucionalismo, reconheceu outros modelos familiares.

Através do artigo 226 da Constituição Federal, a família passou a ser reconhecida como uma entidade descentralizada e democrática, fundamentada no afeto e nas relações pessoais entre seus integrantes, preocupada com a liberdade e a igualdade entre seus membros.

Para Moraes e Teixeira (2013, p. 2.115):

\begin{abstract}
A experiência constitucional brasileira reflete a extraordinária transformação ocorrida na tutela jurídica da família ao longo do sec. XX. Do ponto de vista formal, passa-se de acanhada menção ao casamento civil na constituição de 1891 à ampla determinação dos princípios fundamentais do Direito de Família na Constituição atual. Do ponto de vista substancial, parte-se da previsão na Constituição de 1934, de um modelo único de família fundado no casamento indissolúvel à pluralidade de entidades familiares.
\end{abstract}

A família que até então era disciplinada exclusivamente pelo Direito Privado, através do Código Civil e das leis pertencentes a este ramo do Direito, passou a ter uma interferência 
do Estado, e sob sua tutela passou a ser considerada uma das células principais da formação do indivíduo, sendo o núcleo que expressa a cidadania na sociedade.

Para Hérika Juliana Linhares Maia (2015):

\begin{abstract}
De acordo com o entendimento doutrinário e jurisprudencial, a Lei Maior ao admitir outras formas de convivência de pessoas, como o fez expressamente com a família monoparental e a união estável, não teve a intenção de estabelecer um rol taxativo dos núcleos familiares. Pelo contrário, entende-se que o rol previsto no art. 226 do texto constitucional é meramente exemplificativo, pois o legislador não quis abarcar todas as formas de entidade familiar, apenas tratou de mencionar as mais conhecidas. Sendo assim, conclui-se que as demais modalidades, ainda que não expressamente tipificadas, também gozam de proteção jurídica.
\end{abstract}

Através dessa nova visão da família e da valorização de sua importância na sociedade, observa-se uma mudança em sua formação cada vez mais rápida, pois uma vez que representa o principal núcleo social, de formação do indivíduo, sofre influência direta dos costumes.Sob a ótica do pluralismo jurídico e do neoconstitucionalismo, a valorização dos Princípios Constitucionais da Liberdade e da Igualdade, serviu de alicerce para o reconhecimento de novos modelos de famílias, ainda que não estivessem expressamente elencadas no artigo 226 da Carta Magna, obedecendo-se os preceitos do Estado Democrático de Direito.

No entendimento de Barone (2013, p.15):

\begin{abstract}
Reconhecer somente famílias expressas no texto constitucional implicaria afrontar princípios e valores essenciais, que traduzem e caracterizam o Estado Democrático de Direito, tais como: liberdade, igualdade, solidariedade, fraternidade e autonomia privada. Equivocam-se aqueles que circunscrevem o conceito de família somente às hipóteses mencionadas, esquecendo-se do seu, democrático, igualitário e desmatrimonializado.
\end{abstract}

Através dessa nova visão da família e da valorização de sua importância na sociedade, observa-se uma mudança em sua formação cada vez mais rápida, como forma de acompanhar a evolução social e a mudança de costumes na sociedade, valorizando-se mais as pessoas do que o patrimônio nela existentes.

Para Bruno Ribeiro (2013, p. 27), “a partir desse fenômeno operado na ordem jurídica brasileira especialmente a partir da Constituição de 1988, a família tradicional, que aparecia através do direito patrimonial, agora é fundada no respeito à dignidade de cada um de seus integrantes". 
Assim, a família deixou de ser uma instituição repressora, patriarcal, patrimonizada e hierarquizada para tornar-se uma instituição afetiva, plural, democrática e livre, com seus membros buscando a felicidade e o reconhecimento jurídico dos novos valores a ela atrelados.

A família passou a ser reconhecida como o núcleo de pessoas com identidade afetiva, unidas pela realização pessoal, em busca da felicidade. Podendo-se afirmar ainda que, na sociedade ocidental, houve a transformação de uma família religiosa para uma família afetiva e livre. (SANCHES, 2011, p. 442).

É importante frisar a influência dos costumes e da religião na formação dos novos arranjos familiares e nas mudanças que sofreram ao longo dos tempos, podendo-se observar que um longo caminho de lutas e conquistas foi travado, uma vez que a família surgiu de uma sociedade matriarcal, posteriormente mudando para um modelo patriarcal, tendo o homem como o "chefe" da família e detentor do poder de todas as decisões familiares, chegando-se ao modelo atual, pluralista e democrático, fundamentado nos preceitos constitucionais de igualdade e liberdade.

Ao falar-se em instituição familiar, pode-se observar que apesar da tentativa de padronização e legitimidade, não há um modelo experimentado que explique todas as práticas sociais, com experiências, discursos, vivências, onde a vida extrapola todos os modelos e a narrativa não dá conta das experiências, com uma multiplicidade de aspectos que envolvem a vida na sociedade e na família (MIRANDA, 2012, p. 241).

Através dos costumes outro importante efeito de transformação da entidade familiar pôde ser observado: é a repersonalização das relações de família, onde esta passa a ser moldada de acordo com os interesses dos seus membros, tornando cada família única, sendo este um fator de relevante importância para a aplicação do Direito.

Para Wambier, a cara da família moderna mudou, atualmente existindo flexibilidade e intercambialidade de papéis, e, indubitavelmente, mais intensidade no que diz respeito a laços afetivos. (WAMBIER, 1993, p. 83)

Com a ampliação dos direitos de cidadania promulgados pela Constituição Federal em 1988 e a promulgação do Código Civil em 2002, verifica-se alterações significativas na dimensão da legalidade do direito de família, ampliando-se a sua concepção, consequentemente, a proteção a ela destinada, contemplando-se os diferentes arranjos familiares.

Assim, as relações jurídicas privadas advindas das famílias devem ser tuteladas, sobretudo quando ameaça os Princípios Constitucionais. É neste sentido que se pode dizer 
que a constitucionalização do direito privado existe na mesma proporção em que existe a supremacia da Constituição em relação às demais normas.

Atualmente, a Constituição e o Código Civil não delimitam espaços diferenciados ou antagônicos, representantes do direito público e direito privado, respectivamente, mas devido a uma unidade hermenêutica, o Código Civil deve ser interpretado e aplicado segundo a Constituição e não de modo contrário como ocorria em tempos atrás, reflexo da constitucionalização do direito civil.

Essa nova visão da família, constitui-se um paradoxo, um duplo movimento "privatização versus socialização da família" (ARAUJO, 2011, p. 436), ou seja, ao mesmo tempo em que houve maior valorização da intimidade e qualidade das relações interpessoais, houve também maior intervenção do Estado sobre o grupo familiar.

Com a constitucionalização do Direito Civil, as instituições familiares deixaram de ser tuteladas unicamente pelo Direito Privado através do Código Civil e passaram a ser tutela do Estado que através do Direito Público, tem ações afirmativas voltadas ao seu desenvolvimento e a efetivação de cidadania de seus membros.

\section{POLÍTICAS PÚBLICAS VOLTADAS À FAMÍLIA}

No contexto democrático e cidadão do Estado trazido pela Constiuição Federal de 1988, as Políticas Públicas ganharam acentuada importância, uma vez que não basta a Constiutição Federal dispor de enorme gama de direitos sociais e tratar dos instrumentos para sua realização, é necessário também, a sua efetivação na sociedade.

As Políticas Públicas surgem com novas propostas de transferência de renda, através de formas atuais e diferenciadas de enfrentamento à pobreza, com inovadores instrumentos de proteção social, distanciando-se de práticas antigas, ineficazes e insuficientes, em um contexto neoliberal, redirecionando a política social brasileira nas famílias de baixa renda. (CARNEIRO,

2010, p.12)

Os preceitos de cidadania ganharam maior notoriedade a partir da Constituição Federal de 1998, em um contexto que permitia informar que os direitos formalizados na Constituição Federal estariam a poucos passos da efetiva e almejada proteção social na direção da cidadania apontando para a formulação e efetivação de políticas sociais com ações cada vez mais compensatórias, focalizadas e pontuais. (SILVA, 2013, p. 157) 
Assim, o Estado passou a desenvolver ações para garantir um mínimo de bens e serviços sociais, como moradia, educação, saúde, o reconhecimento desses direitos é a afirmação e consolidação da cidadania.

As políticas públicas não trazem uma única, ou melhor, definição acerca de seu conceito. A ideia trazida por Leonardo Secchi em seu livro Políticas Públicas: conceitos esquemas de análise, casos práticos problematiza-se, qualquer definição de políticas públicas é arbitrária, por se tratar de uma diretriz elaborada para enfrentar um problema público exigindo trânsito em diversas áreas das ciências humanas para sua consecução. (SECCHI, 2012)

Quanto à área de atuação, deve-se ressaltar que o campo das políticas públicas é eminentemente multidisciplinar. Diversas áreas do conhecimento, tais como ciência política, filosofia, psicologia, sociologia, administração, economia, serviço social, possuem interfaces com as políticas públicas, de modo que é difícil, se não arriscado, designar $a$ área por excelência. (SOUZA, 2006)

Já quanto à efetividade, pode-se afirmar que as políticas públicas garantem a efetivação de cidadania pelo Estado Social, pois no entendimento de Eros Grau apontado em seu livro O Direito posto e o Direito Pressuposto, a legitimidade do Estado Democrático de Direito está ligada à realização de políticas públicas, caracterizadas por todas as formas de intervenção do

Estado (GRAU, 1998).

Deste modo, as políticas públicas surgiram para garantir aos indivíduos os direitos previstos constitucionalmente como forma de concretizar a cidadania, pois no entendimento de Smanio, tais políticas só ganham legitimidade nesta perspectiva. (SMANIO, 2013, p.13).

Tendo em vista que, sendo a família uma das principais Instituições Sociais, módulo estruturante da sociedade, responsável pelo desenvolvimento do cidadão, é demanda do Estado prestar apoio e condições dignas de desenvolvimento entre seus membros, com o dever de garantir a eles os direitos fundamentais previstos constitucionalmente. Assim, como aborda Gustavo Tepedino em seu livro Temas de Direito Civil, é preciso estar atento para o fato de que é característico do chamado Estado Social, intervir em setores da vida privada tendo em vista proteger o cidadão, postura com a qual, segundo Tepedino é imprescindível em um Estado liberal que prestigia a liberdade (TEPEDINO, 2009, p. 21).

No entendimento de Amaral, “a família é, portanto, uma construção social que varia segundo as épocas, permanecendo, no entanto, aquilo que se chama de 'sentimento de 
família'. Que se forma a partir de um emaranhado de emoções e ações pessoais, familiares e culturais, compondo o universo do mundo familiar”. (AMARAL, 2001, p. 03).

Assim, sendo a família uma Instituição social em constante mudança, necessário se faz analisar a criação de políticas públicas que se tornem efetivas e adaptadas a estas mudanças.

\title{
6. POLÍTICAS PÚBLICAS VOLTADAS AOS NOVOS ARRANJOS FAMILIARES
}

Para entender a família como instituição social beneficiária de políticas-públicas e programas sociais, necessário se faz compreender a sua importância como núcleo formador do indivíduo, reconhecer sua pluralidade, só assim, tem-se a cidadania efetivada.

É imprescindível a efetivação de políticas públicas promovidas pelo Estado na concretização da cidadania proposta pela Carta Magna, preceito de um Estado Demopcrático de Direito.

Mas não é uma tarefa fácil, pois no entendimento de Alencar Frederico Margraf:

\begin{abstract}
Diante das inúmeras percepções a respeito do que é primordial e indispensável, passase a verificar a dificuldade de colocar em prática os programas de inclusão social ou de redução da exclusão social no Brasil. A diversidade cultural e o desconhecimento da realidade social pelo legislador, bloqueiam a ampliação destas percepções, até mesmo porque a distância da realidade é uma das principais críticas existente com o sistema de representação política brasileiro. Assim sendo, as respostas à pobreza e às desigualdades estão ligadas a forma de como se constitui o entendimento e reconhecimento das determinantes sociais. (MARGRAF, 2015, p. 108)
\end{abstract}

Para que as políticas-públicas voltadas à família se tornem efetivas, também se faz necessário conhecer os novos arranjos familiares surgidos a partir da dinâmica social em que se encontram os núcleos familiares, bem como a compreensão de suas novas formas de organização que vão se modernizando de acordo com o contexto social existente.

Para Kaloustian \& Ferrari (1994), a família é o espaço indispensável para a garantia da sobrevivência e da proteção integral dos filhos e demais membros, independentemente do arranjo familiar ou da forma como vêm se estruturando.

Ocorre que os programas de políticas públicas voltadas à família são destinados a abranger de forma geral modelos familiares tradicionais, ou seja, aqueles previstos explicitamente no artigo 226 da Constituição Federal, a exemplo das famílias formadas pelo casamento, pela união estável ou as famílias monoparentais. 
Observa-se que na implementação das Políticas Públicas não são levadas em consideração, as famílias contemporâneas emergentes na sociedade, suas diversidades e peculiaridades, embora este tipo de atenção por parte do Estado seja essencial para um planejamento e para a implementação de políticas públicas mais eficazes.

Para Cunha:

Os estudos sobre a composição e a organização das famílias revestem-se de grande importância para a formulação de políticas públicas. A análise de diferentes formas de se considerar as famílias em programas sociais fornece o ferramental necessário para que se conclua que um melhor conhecimento sobre elas é extremamente importante, na medida em que estão relacionadas a diversos fatores, desde a geração de externalidades até os impactos mútuos provocados pelas políticas sociais nos seus objetivos, dependendo de como se apresenta a organização familiar. (CUNHA, 2013. p. 220)

Os diversos modos de famílias contemporâneas surgiram com a evolução social e a quebra de paradigmas fundamentados na abertura constitucional, tornando-se necessário a observação dessas novas situações na implementação de políticas públicas, e, sobretudo, no que diz respeito a sua efetividade em relação às particularidades dos novos arranjos.

Na visão da doutrina moderna:

Visto que a fundamentação para o Direito de Família ocorre majoritariamente a partir da Constituição Federal, com reflexos nas demais legislações citadas anteriormente e que estas emergiram para procurar atender às necessidade das pessoas e tornar sua aplicação prática de forma rápida e definitiva, considera-se imprescindível a criação de mecanismos que tornem efetivas e executáveis a aplicação de tais legislações, devendo ser respeitadas e defendidas pelos operadores da Justiça. (SOUZA, BELEZA e ANDRADE, 2012).

Assim, torna-se urgente a discussão da mudança de paradigmas em relação à implementação de programas sociais voltados aos novos arranjos familiares, independente da forma como são constituídos. Não se pode falar em políticas públicas eficazes sem dar destaque à família como mola propulsora dos programas de governos.

Ajudar a família é uma importante possibilidade de alcançar o desenvolvimento digno da sociedade e garantir os preceitos de cidadania.

Em linhas gerais, surgem várias indagações de ordem prática na aplicação efetiva das políticas públicas para as famílias contemporâneas, a exemplo das famílias pluriparentais, que não têm definidas algumas situações, como, por exemplo, quem terá direito a cadastrar-se nos programas oferecidos pelo Estado, se o pai/mãe socioafetivos ou pai/mãe biológicos, ou ainda, se os dois, e sendo pago a todos, se o benefício deverá ser dividido entre eles ou se deverá pago integralmente a cada um.

São dúvidas suscitadas, porque as Instituições de Assistência Social não estão preparadas para cadastrar estes tipos de famílias, já nos casos das famílias poliafetivas, a 
discussão gira em torno de quem poderá usufruir dos programas sociais, como os programas de auxílio à moradia, já que se trata de dois ou mais companheiros vivendo simultaneamente no mesmo núcleo familiar, e, assim como estas questões, surgem várias dúvidas de ordem prática envolvendo diversas famílias contemporâneas.

As questões levantadas trazem problemas que certamente acabarão desaguando nas portas do Judiciário, carecedores de um posicionamento acerca da possibilidade de cadastro destas famílias em programas de políticas públicas estabelecidos.

No entendimento de Clarice Seixas Duarte, o processo de implementação das políticas públicas, requer quatro fases, a saber, a formulação, execução, avaliação e fisscalização. Cada uma dessas fases deve observar as diretrizes e princípios inscritos na Constituição Federal, para que se tenham critérios bem definidos nas decisões judiciais que envolvem a efetivação das políticas públicas (DUARTE, 2013).

O judiciário tem um papel primordial no controle da aplicação das políticas públicas, devendo verificar se o seu processo de implementação observa os elementos objetivos que devem estar presentes para que se tornem efetivas, atendendo os direitos sociais previstos constitucionalmente.

\section{CONSIDERAÇÕES FINAIS}

Mesmo que ainda não tenhamos um delineamento muito claro sobre a implementação de uma determinada política pública por parte do Estado, os indivíduos têm o direito de exigi- las em conformidade com a Constituição Federal.

Assim, observa-se que uma vez reconhecidas juridicamente, as famílias contemporâneas passam a ter o direito de utilizar os programas sociais implementados pelo Estado, como forma de garantia de seus direitos fundamentais e exercício de cidadania, preceitos estabelecidos constitucionalmente.

Desse modo, caso o Estado seja omisso na implementação ou reforma das políticas públicas, de forma a abranger também os novos arranjos familiares que vêm surgindo na sociedade contemporânea, o Judiciário, utilizando-se das fontes do direito, como respaldo jurídico de interpretação, terá que se posicionar no tocante a utilização destes programas por parte do Governo, para que se tornem eficientes a qualquer tipo de família, seja tradicional ou contemporânea, caso contrário, ocorrerá um enorme número de demandas judiciais, daí a necessidade urgente de um posicionamento do Estado acerca desta questão. 


\section{REFERÊNCIAS}

AMARAL, Célia Chaves Gurgel do. Família às avessas: gênero nas relações familiares de adolescentes. Fortaleza: UFC, 2001.

ARAÚJO, Maria de Fátima. Paradoxos da família contemporânea. Psicologia e sociedade. Vol.

23 iss. 2. 0102-7182.

2011.

BARONE, Lourdes Regina Jorgeti. Jurisdição de família como forma de efetivação da cidadania. 2013. Tese. (Dourado em Direito) - Universidade Presbiteriana Mackenzie. São Paulo, 2013.

CARNEIRO, Annova Míriam Ferrreira. A centralidade da família no programa bolsa família: a análise referenciada no Programa em São Luiz - MA. 2010. Tese. (Dourado em Políticas Públicas) - Universidade Federal do Maranhão. Maranhão, 2010.

CARVAlHO, José Murilo de. Cidadania no Brasil, um longo caminho. Rio de Janeiro: Civilização Brasileira, 2010.

CUNHA, José Onofre Gurjão Boavista da. Capital social, Família, e redução da Pobreza:

um percurso na literatura. 2013. Tese. (Doutorado em Família na Sociedade Contemporânea)

- Universidade Católica de Salvador. Bahia, 2013.

DUARTE, Écio Oto Ramos. O Neoconstitucionalismo como Antipositivismo Jurídico: uma teoria do direito e do Estado em face do cosmopolitismo jurídico. 2013. Tese. (Doutorado em Direito) - Universidade de Fortaleza. Ceará, 2013.

FALAVignA, Maria Clara Osuna Diaz. Os Princípios Gerais do Direito e os Standards Jurídicos no Código Civil. 2007. (Doutorado em Direito) - Universidade de São Paulo. São Paulo, 2007. 
FERRAJOLI, Luigi. CORDÓBA, Marcílla Gema. Constitucionalismo y garantismo, Bogotá: Universidad Externado de Colombia, 2009.

FERRAZ, Sampaio Tercio. Introdução ao estudo do direito. São Paulo: Atlas, 2015.

GALVÃO, Jorge Octávio Lavocat. O neoconstitucionalismo e o fim do Estado de Direito.

2012. Tese. (Doutorado em Direito) - Universidade de São Paulo. São Paulo, 2012.

GRAU, Eros Roberto. O Direito posto e o Direito Pressuposto. São Paulo, Malheiros, 1998.

GUTIÉRREZ, Marcela. Pluralismo jurídico y cultural en Colombia. Revista Derecho

del

Estado. 0122-9893. Fasc. 26,

2011.

KALOUSTIAN, S. M; FERRARI, M. Introdução. In: KALOUSTIAN, S. M. (org.). Família brasileira, a base de tudo. São Paulo-Brasília: Cortez-Unicef, 1994. p. 11-15.

MAIA, Hérika Juliana Linhares. Adoção homoparental conjunta: famílias socioafetivas e a concretização do melhor interesse da criança e do adolescente. Doutrinas Essenciais de Direito Constitucional. Vol. 8/2015. Ago. 2015. DTR/2015/11508. 2015. p. 697 - 718.

MARGRAF, Alencar Frederico. Programa Bolsa Família: a distribuição de renda como garantia ao mínimo existencial. Revista dos Tribunais. vol. 961/2015. Nov/2015. DTRL2015\13361. 2015. p. $105-126$.

MARTINS, Samir José Caetano. Neoconstitucionalismo e seus Reflexos nas Relações Jurídicas Privadas: Em Busca de Parâmetros de Aplicação Direta dos Direitos Fundamentais. Revista de Direito Privado. vol. 30/2007. Abr - Jun 2007. p. 265 - 304.

MASCARO, Alysson Leandro. Crítica da legalidade e do Direito Brasileiro. 2. ed. São 
Paulo: Quartier Latin, 2008.

MIRANDA, Alina Silva Sousa de. "União indissolúvel e perpétua?": Modernidade e expressões familiares à época da secularização dos casamentos (1890-1930). 2012. Tese. (Dourado em Direito) - Universidade de São Paulo. São Paulo, 2012.

MORAES, Maria Celina Bondim; TEIXEIRA, Ana Carolina Brochado. Comentários à

Constituição do Brasil. São Paulo: Saraiva, 2013.

RIBEIRO, Hélcio; BERTOLINI, Patrícia Tuma; SMANIO, Gianpaolo (Coords.). O Direito e as Políticas Públicas no Brasil. São Paulo: Atlas, 2013.

RIBEIRO, Bruno Marques. Relações familiares simultâneas à luz da ordem civil constitucional. 2013. Dissertação (Mestrado em Direito) - Universidade Federal de Uberlândia. Minas Gerais, 2013.

SANCHES, Patricia Corrêa. Mudança de gênero e da identidade de nome. In: DIAS, Maria

Berenice. Diversidade sexual e direito homoafetivo. São Paulo: Revista dos Tribunais, 2011.

SANCHÍS, Luís Prieto. Sobre o Neoconstitucionalismo y sus Implicaciones. In: Justicia

Constitucional y Derechos Fundamentales. Madrid: Trotta, 2003.

SILVA, Leda Regina de Barros. Assistência social, cidadania e enfrentamento da pobreza:

as falas dos usuários em Campos dos Goytacazes. 2013. Tese. (Doutorado em Serviço Social)

- Universidade Estadual do Rio de Janeiro. Rio de Janeiro, 2013.

SIMIONI, Rafael Lazzarotto. Interpretação jurídica e percepção seletiva: a dimensão organizacional da produção de sentido no direito. Revista Brasileira de Direito, jan.-jun. 
2015 - ISSN 2238-0604. 2015. p. 135-

147.

SMANIO, Gianpaolo Poggio; BERTOLINI, Patrícia Tuma. SMANIO, Gianpaolo (Coord.). O

direito e as políticas públicas no Brasil. São Paulo: Atlas, 2013.

SOUZA, Celina. Políticas Públicas: uma revisão da literatura. Sociologias. v. 8, n. 16, jul./dez. 2006. Porto Alegre, 2006. p. 20-45.

SOUZA, Alinne Bianca Lima; BELEZA, Mirna Carla Moreira; ANDRADE, Roberta Ferreira Coelho de. Novos arranjos familiares e os desafios ao direito de família: uma leitura a partir do Tribunal de Justiça do Amazonas. PRACS: Revista Eletrônica de Humanidades do Curso de Ciências Sociais da UNIFAP. ISSN 1984-4352 n. 5. Macapá, dez. 2012. p. 105 119. Disponível em: http://periodicos.unifap.br/index.php/pracs.

STRECK, Lênio Luiz. Hermenêutica Jurídica e (em) crise, uma exploração hermenêutica da construção do Direito. ed. 11. Livraria do Advogado: Porto Alegre, 2013.

TEPEDINO, Gustavo. Temas de Direito Civil. Rio de Janeiro: Editora Renovar, 2009.

VENERIO, Carlos Magno Spricigo. Universidade e Comunidade: o ethos comunitário das universidades catarinenses mantidas por fundações municipais de direito privado - uma abordagem a partir do pluralismo jurídico. 2012. Tese. (Doutorado em Direito) Universidade Federal de Santa Catarina, Santa Catarina, 2012.

WAMBIER, Teresa Celina de Arruda Alvim. Um novo conceito de família: reflexos doutrinários e análise de jurisprudência. In: TEIXEIRA, Sálvio de Figueiredo (Coord.) Direitos de Família e do Menor. 3. ed. Belo Horizonte: Del Rey, 1993. 